\title{
Managing the Organization Culture in Domestic and Foreign Operations
}

\author{
Hany H. Makhlouf ${ }^{1, *}$ \\ ${ }^{1}$ School of Business and Public Administration, University of the District of Columbia, 4200 Connecticut Avenue, \\ N.W., Washington, D.C. 20008, USA \\ *Correspondence: School of Business and Public Administration, University of the District of Columbia, 4200 \\ Connecticut Avenue, N.W., Washington, D.C. 20008, USA. E-mail: hmakhlouf@udc.edu
}

Received: JDecember 9, 2016 Accepted: January 3, 2017 Online Published: January 5, 2017

doi:10.5430/wjss.v4n1p22 URL: http://dx.doi.org/10.5430/wjss.v4n1p22

\begin{abstract}
Organizations develop their own cultures that reflect their shared values, norms, and preferred approaches to attain their goals and solve problems. Such organization cultures condition the employees ways of thinking; interpersonal relations; and perceptions of what is the right thing to do and what is not, what is an acceptable pattern of behavior and what is not, and what is good for the enterprise and what is not. Organization cultures, however, encounter multiple challenges once companies expand their operations geographically, particularly when they enter foreign markets and start to operate subsidiaries in diverse cultural, political, sociological, and economic environments. A main question addressed in this paper is: To what extent can and should organization cultures remain intact in highly diverse environments? To address this problem, the meaning and significance of organization cultures will first be explored; then the analysis will focus on the challenges that multinational enterprises face in managing their organization cultures in the complex global environment.
\end{abstract}

Keywords: multinational corporations, corporate culture, countercultures, subcultures, international mergers and acquisitions, cultural shock, cultural conflict, universalism, and particularism

\section{Introduction}

Organization cultures emerge as organizations grow and begin to experience successes and failures, and begin to encounter challenges that require immediate reaction and behavioral adjustments. In those organizations' early years, the founders' attitudes, assumptions and prior experiences plant the seeds of organization cultures that reflect specific values and behavioral patterns, they believe to be best for solving problems, and for helping the firm to attain new goals and objectives. As Madu (2011) observes, "the values promoted by the leaders (and founders) have a significant impact on the values exhibited by the organization.... What the leaders emphasize (consistently) and measure (in performance evaluation) overtime can have a great impact on the organization's culture” (p. 4).

Schein (1990) also recognizes the role of founders and other leaders in the formation of the organization's culture, but adds that their impact is only one of two ingredients in the pot, the other being the group's common experience. Thus, he explains that 'the group learns from its experience what parts of the (leaders') belief systems works for the group....The joint learning then gradually creates shared (values and) assumptions” (p. 115). In addition to examining the meaning, significance, and impact of organization cultures, this paper addresses the issues and the problems involved in managing a unified organization culture throughout a multinational enterprise, particularly if it grows through mergers and acquisitions, and would have to coordinate and unify multiple sets of values and norms.

A major question to be explored in this paper is: To what extent organization cultures can and should remain intact in a highly diverse global market environment? In addressing this question, which is not adequately explored in current literature, the meaning and impact of organization culture will first be discussed. After that, the focus of the paper will be mostly on the issues that complicate the management of organization cultures in multinational corporations as well as the need for the organization culture's adjustment and adaptation in a multinational environment.

It is hoped that this paper will be of benefit both to international managers and students of culture and international business. It is also hoped that the analysis and conclusions will contribute to the literature on organization cultures, particularly as related to multinational enterprises. A disregard of the issues outlined in this study can have a negative 
impact on the success of international operations, including international mergers and acquisitions.

\section{Understanding the Concept}

Scholars differ in their definitions of organization culture, but the differences among them are not substantial. One short definition that captures the essence of most definitions refers to organization culture as "a set of norms and values that are widely shared....throughout the organization” (O’Reilly and Chatman, 1996). Schein (2004) gives a slightly more elaborate definition, stating that an organization culture is "a dynamic phenomenon that surrounds organizations at all times, being constantly enacted routines, rules, and norms that guide and constrain behavior". To add to our understanding of the importance of organization culture, Petersens and Ibsen (2013) also argue that it is like a kind of glue that holds or bonds the members of the organization together (p. 8). Another useful depiction of organization culture, provided by Hofstede (1988), is that it is a kind of a "collective programming of the minds" (p. 179).

\section{Strong versus Weak Cultures}

The extent of the group's internalization and commitment to the organization's common values reflects the relative strength of the organization culture, which, in turn, influences its impact on behavioral patterns, as well as the degrees of homogeneity, conformity to the rules, and consistency in problem handling. Thus, an organization culture is considered to be strong when it is widely shared and accepted by the members of the group, and it is considered to be weak when the core organizational values are not deeply internalized and the group is "loosely knit" due to a high rate of employee turnover, physical distance, or some other reason (Shahzad et al, 2012, p. 977).

\section{Dominant Cultures, Sub-Cultures, and Counter-Cultures}

In the early or formative years of a relatively small organization, management's primary effort is to see emerging one dominant culture that reflects the preferred ways of thinking and behaving. As such organizations grow, sub-cultures and counter-cultures may eventually emerge, and also impact employee thinking and behavior. Although sub-cultures that emerge may not clash with the dominant culture, counter-cultures most likely do. As McShane and Glinow (2013) point out, "subcultures may emerge throughout divisions, geographic regions (like foreign units), and occupational groups” (p. 409), but counter-cultures may challenge and conflict with top management values and the dominant culture (McShane and Glinow, 2013, p. 409).

\section{Depth of the Organization Culture's Impact}

Organization cultures are like a double edged sword. Their impact can be positive or negative as far as attaining organizational goals and objectives is concerned. The depth of their impact, however, depends on how strong they are. . Understandably, a weak culture would not influence thinking and behavior to the extent a strong culture would. More specifically, a reasonably strong organization culture can: :

1. Help mold individual and group thinking about the mission of the enterprise and the importance of its continued existence

2. Hold the members of the organization emotionally together in good and bad times

3. Guide the members of the organization in their relations and interactions with the external environment

4. Influence how problem-solutions are to be approached and decisions are to be made

5. Shape attitudes towards organizational priorities, performance and ethical standards, and interpersonal relations

6. Impact how the organization treats its stakeholders, including customers, workers, etc.

7. Influence resource allocation

8. Influence attitudes towards innovation and change

9. Impact attitudes toward individuals with authority

10. Influence perceptions regarding preferred choices among alternative avenues to achieve desirable ends 
11. Condition the way to react to crises and substantial conflicts and disagreements

12. Guide employees in relation to political correctness and open expression of disagreements.

A strong culture, however, can be difficult to change and, at times, can obstruct management's desire to introduce new ideas and technologies, as will be further explained later on in this paper. In short, the organization culture can have a multitude of benefits and costs, but for the most part, and if properly managed, it helps in giving the organization a unique character and personality that distinguish it from the rest. Although organizations frequently try to copy from similar entities what may be considered to be "best practices", and isomorphism (imitating others) makes many of them look alike, at least to some degree, every organization ends up having a culture and a character of its own. As already noted, top management and the organization's experiences and environments inevitably make it different from the rest.

\section{Characteristics of Organization Cultures}

Organization cultures have five major characteristics: First, They are semi-open systems that provide stability and allow continuity, but they can still change, slowly and in small steps, due to internal and/or external stresses. Secondly, cultures are learned and internalized by new employees over a period of time through interpersonal relations and communication, observation, and formal training (acculturation/socialization).Thirdly, good company performance strengthens a dominant organization culture and lessens the likelihood of the emergence of challenging and demoralizing counter-cultures. Fourth, cultures can be strengthened by consistent management adherence to the organization's core values, norms, and policies. Fifth, dominant cultures can be strengthened and sustained when the employees' compensation and reward systems are tied, to some degree, to the extent of internalization of the company's core values, norms, and overall culture.

\section{Hofstede's Dimensions of Culture}

Hofstede (1980) identifies four dimensions that contribute to our understanding of the diverse environments of multinational corporations: power distance (e.g. psychological distance between superiors and subordinates). individualism (as opposed to collectivism), uncertainty avoidance (as opposed to willingness to take the initiative and assume some risk), and masculinity versus femininity (gender role differences).Thus, the more widespread the operations of a firm, the greater the diversity encountered by managers along these dimensions, and the greater the incidents of cultural clashes and shocks that expatriate managers encounter as they are given a foreign assignment or are rotated from one foreign subsidiary to another.

\section{Positive versus Negative Consequences of Organization Cultures}

As previously indicated organization cultures can have both positive and negative consequences that impact performance, internal/external conflicts and goal attainment. In regard to the positive contributions, it is important to emphasize its impact in promoting and maintaining consistency, conformity, homogeneity, continuity, stability, risk taking, standardization, predictability, and compliance with group standards and values. Therefore, shrewd managers can use it as a control tool and as one of the means to raise the organization's competitive advantage. On the other hand, an organization culture can cause rigidity, slow reaction to new challenges, deter experimentation with new ideas, delay adjustment to new realities in the external or internal environments, cause stagnation, and strengthen individual and group resistance to innovation and change. These negative consequences, if allowed to persist, can doom the organization or, at least, subject it to conflicting thinking and behavioral patterns.

\section{Managing the Organization Culture}

For managers to succeed in using the organization culture as a control tool, they themselves have to internalize it, and as mentioned earlier, remain consistent in advocating the organization's core values, norms, rules, and standards. In addition, managers should:

1. Recruit employees who would most likely accept and conform to the same values and norms

2. Use conformance to core values and norms in performance evaluation, rewards distribution, and the overall compensation system 
3. Emphasize adherence to core values in official communications

4. Establish orientation and training programs to help employees to accept and internalize core values and norms

5. Be open to justifiable changes in order to avoid having the culture become a cause of stagnation and decline.

\title{
Categories of Values Usually Promoted in Organization Cultures
}

\author{
Tolerance to Criticism \\ Integrity and honesty \\ Accountability and Ownership of One’s Mistakes \\ Fairness and Giving Credit \\ Result Orientation and Pursuit of Excellence and Efficiency \\ Respect for Others Regardless of Rank \\ Respect for Authority, Rules and Procedures \\ Commitment to the Task and Cooperation for the Common Good \\ Respectful Attitude toward Customers \\ Ease in Upward and Downward Communication
}

Source: Based on Guiso et al, 2013.

\section{Organization Culture in Multinational Corporations}

The challenges of managing the organization culture in a complex organization multiply when a firm expands globally. As Fatehi (1996) observes, "the cultural difference is a major source of difficulty for managing a global firm" (p. 22). Operating subsidiaries in the global market results in hiring employees with diverse cultural backgrounds that may differ, in varying degrees, from the company's organization and home cultures and values. Presence in the global market also necessitates dealing with customers, suppliers, and government officials who also have multiple cultural backgrounds, and different perceptions and attitudes toward power, time, family, authority and responsibility, bribery, environmental issues, and many other important considerations. Thus, trying to extend the parent company's cultural values, without adaptations and adjustments, may be resented or labeled as a manifestation of ethnocentrism, lack of empathy or cultural imperialism.

\section{Cultural Conflicts in International Mergers and Acquisitions}

Since cultures are learned, the managers in the parent company may do the best they can to communicate the organization's core values to the subsidiaries but they may be resented or misunderstood, and, thus, not have the same impact as they do in the parent company. Fatehi (1996) demonstrates how national cultures condition workers ways of thinking about the proper ways to manage, using as an example workers in France as opposed to Sweden. He points out that the "national cultural values that workers have internalized as a result of life-long socialization are brought into the cultural mix within the multinational company.... Due to such socialization, workers in France would more likely be culturally adjusted to hierarchical systems, as opposed to Swedish workers who are more oriented to a more egalitarian and participative decision-making” (p. 128).

Wu (2008) also explains what western-based multinational companies culturally encounter in the Chinese market by pointing to three powerful traditional philosophies that western recruiters have to take into consideration in the employee selection process: Confucianism, Taoism, and Buddhism. These philosophies influence how Chinese workers are likely to handle relationships, avoid conflict, build harmony, perceive the exact commitments resulting from the contracting process, emphasize trust building, and exchange favors (p. 172). These philosophical orientations would influence workers thinking and behavior although they may not necessarily be compatible with the parent company's organization culture or core values; hence the potential of a cultural clash.

Multinational companies that grow through mergers and acquisitions have an added cultural challenge because they 
inherit workers and organizations that already have their own history and have developed their own organization cultures. Workers in the acquired firms may resist any substantial cultural changes that their new parent company managers would like to introduce. If the originally independent organization cultures are far apart or are not a perfect fit, the efforts to superimpose one over the other may not succeed.

Many international mergers and acquisitions fail due to clashing cultures. The synergies expected do not often materialize unless there is a good cultural fit. The following examples demonstrate this point:

1. The Daimler-Chrysler Merger: A merger agreement between Daimler of Germany and Chrysler of the United States was announced in 1998, and was described as a merger of equals, with a great deal of enthusiasm and anticipation by the senior managers of both companies. In recognition of the differences in the two companies' cultures and core values, cultural sensitivity training programs were immediately organized. However, those efforts were not sufficient to create a cultural harmony below the level of senior management. A culture clash persisted and eroded the merger's expected synergies. Daimler's culture and core values, for example, emphasized "quality at any cost" while Chrysler's emphasized quality within certain cost and price guidelines in order to appeal to a variety of classes customers. In addition, the management and employee compensation philosophies in both companies were far apart. As a study by Professor Sydney FinkelStein (2002) of the Tuck School of Business at Dartmouth University indicates, "culture clash seemed to exist as much between products as it did among employees" (p. 5). Once the implementation of the agreement began, the "merger of equals" started to look like an acquisition or a takeover by the more prestigious Daimler and shortly after employee morale and profitability at Chrysler started to decline. The merger was, therefore, a failure. Commenting on the reasons behind the merger and its final failure, Appelbaum et al (2009) state that "the intentions of Daimler -Chrysler were admirable for technology sharing, market growth,(and) shared resources but a true evaluation of cultural fit never successfully materialized resulting in a predictable failure” (p. 37).

2. Ford-Volvo Takeover: The failure of Ford's takeover of Volvo is also indicative of the lack of a perfect cultural fit. For example, Ford had a greater centralization of decision making authority than Volvo. Noting this difference, Appelbaum et al (2009) state that "at Ford, engineers are not allowed to make decisions and all information are passed up the chain to managers, while engineers made the decisions at all levels at Volvo... Ford, (however) was maneuvering Volvo into the Ford way of running the business” (p. 45). A further clarification of the cultural and managerial style conflicts is reflected in another Appelbaum et al (2009) comment that "Ford executives were sent to meetings (at Volvo) knowing that they did not have authorization to make decisions that Volvo executives would be able to do.... (Thus) Volvo lost the days of speedy, flexible and turning on a dime decision making” (p. 45).

\section{The Limits of the "Change Agent” Role of Multinational Corporations}

Multinational corporations have been described as global change agents. They create new demand for their products in the markets they enter; thus, change consumption patterns and life styles in multiple, culturally diverse countries. They also introduce new technologies, norms, and management know-how in the host countries through their subsidiaries and affiliates. But they have to be highly selective and culturally sensitive as they introduce new values and norms, both within and outside their foreign subsidiaries, that may conflict with the host countries' core values and acceptable practices. Using the food service industry in India as an example of the importance of cultural sensitivity, Phatak et al (2005) point out that "the Hindu religion considers the consumption of beef to be both unethical and immoral....To succeed in India, therefore, companies in the food industry must respect this precept” (p. 517).

\section{Impact of Cultural Universals}

Despite the fact that many expatriates experience a cultural shock upon arrival to assume their duties at some foreign subsidiaries, there are some cultural universals that pervade many cultures. Hill and Hult (2017) argue, for example, that "some universal notions of morality are found across cultures" (p. 143). Also, according to Hodgetts and Luthans (2003), some aspects of culture, including some "ideas and practices, can be applied everywhere without modification” (p. 125). Phatak et al (2005) as well provide examples of universal moral values and norms, namely, truthfulness, respecting other people's property (as opposed to stealing other people's possessions), and fairness in transactions (p. 621-622). Thus, the greater the number of universal values around the world, the easier for expatriate 
managers to handle foreign assignments, and the more effective he/she would likely become. The existence of cultural universals, however, does not negate the reality of having to face many manifestations of cultural conflicts that necessitate deep learning and adjustment by expatriate managers. As Kefalas (1990) observes, "even the most carefully chosen employees may not be perfectly suited to the job assignments or the country conditions” (p. 436); hence the need for a thorough training for international managers in order to create a better understanding of the scope and impact of universalism versus particularism in cross-cultural interactions.

Table 1. Universalism versus Particularim Orientation

\begin{tabular}{ll}
\hline High Universalism Countries & High Particularism Countries \\
\hline The United States & Indonesia \\
Australia & China \\
Germany & Thailand \\
Sweden & Mexico \\
United Kingdom & Argentina \\
\hline
\end{tabular}

Source: Based on Hodgetts and Luthans, 2003.

\section{Conclusion}

Companies that operate over a wide geographic area, particularly multinational companies that operate in many culturally diverse markets around the world, may find it difficult to have one unified organization culture throughout their network of branches, subunits, and subsidiaries. The more widely dispersed their operations, the more likely multiple subcultures would emerge and impact their images and performance. Those subcultures may co-exist with the dominant parent company culture, and impact operations in a positive or negative manner. Thus, management's challenge is to see that the organization's core values and norms are not undermined by the rise of sub-cultures and counter-cultures. Having conflicts between the dominant culture and any emerging sub-cultures can lead to the downfall of the entire enterprise. In many mergers and acquisitions, cultural conflicts, which cannot be resolved, can be responsible for their eventual failure. Therefore, astute managers have to carefully manage their company's organization culture and subcultures so that collectively they would have the desirable impact on performance, and continue to reflect positive shared values, assumptions, and perspectives throughout the company's network of operating units. .

\section{References}

Appelbaum, S. H., Roberts J., \& Shapiro B. (2009). Cultural Strategies in M\&As: Investigating Ten Case Studies. Journal of Executive Education, 8(10), 33-57.

Fatehi, K. (1996). International Management: A Cross Cultural and Functional Perspective. Saddle River, N. J.: Prentice Hall.

Finkelstein, S. (2002). The Daimler-Chrysler Merger. Tuck School of Business at Dartmouth, 1-8.

Guiso, L., Sapienza P., \& Zingale L. (2013). The Value of Corporate Culture. Journal of MIT Economics, 1-20. https://doi.org/10.3386/w19557

Hill, C. V., \& Hult T. (2017). International Business. New York, N. Y.: McGraw-Hill Education.

Hofstede, G, (1980). Culture's Consequences: International Differences in Work-Related Values. Newburry Park, CA: Sage.

Hofstede, G., Neuijen B., Ohayv D., \& Sander G. (1990). Measuring Organizational Cultures. Administrative Science Quarterly, Cornell University, 288-318.

Hodgetts, R., \& Luthan F. (2003). International Management. Boston, MA: McGraw-Hill-Irwin.

Kefalas, A. G. (1990). Global Business Strategy. Cincinnati, Ohio: South-Western Publishing.

Lee, S. J., \& Shah-Hosseini S. (2013).How Does an International Company Ensure its Culture Remains Intact While Also Be Flexible. Retrieved in 2016 from Cornell University, ILR 
http://Digitalcommonsilrcornell.edu/student/23/

Madu, B. C. (2011, October). Organization Culture as a Driver of Competitive Advantage. Journal of Academic and Business Ethics, 1-9.

McShane, S., \& Glinow M. (2013). Organizational Behavior. Boston, MA: McGraw Hill-Irwin.

O’Reilly, C., \& Chatman J. (1966). Culture and Social Control: Corporations, cults, and Commitment. In Barry Shaw and L. Cummings (Eds.). Research in Organizational Behavior. Connecticut: JAI Press, Inc.

Owoyemi, O., \& Ekwoaba J. (2014). Organizational Culture: A Tool for Management to Control. Motivate and Enhance Performance, 3(1), 168-177.

Petersens, S., \& Ibsen K. (2013, May). Corporate Culture in a MNC. Stockholm School of Economics Thesis in Management.

Phatak, A. V., Bhagat R., \& Kashlak R. (2005). International Management. Boston, MA: McGraw Hill- Irwin.

Ralston, D. D. (1997). The Impact of National Culture and Economic Ideology. Journal of International Business Studies, 28(1), 177-203. https://doi.org/10.1057/palgrave.jibs.8490097

Schein, E. (1985). Organizational Culture and Leadership. San Francisco, CA: Jossey-Bass.

(1990, February). Organizational Culture. American Psychologist, 109-119.

Schneider, S. (2003). Managing Across Cultures. Essex: Parson Education, Ltd.

Shahzad, F., Luqman R., Khan A. R., \& Shabbir L. (2012, January). Impact does Organizational Culture on Organizational Performance: An Overview. Interdisciplinary Journal of Contemporary Research in Business, 3(9), 975-985.

Steen, E. V. D. (2010, Winter). On Origins of Shared Values and Corporate Culture. Rand Journal of Economics, 41(4), 617-648. https://doi.org/10.1111/j.1756-2171.2010.00114.x

Weber, R., \& Camerer C. (2001, April). Cultural Conflict and Merger Failure. Management Science, 49(4), 403-415.

Wu, J. (2008, December). An Analysis of Business Challenges Faced by Foreign Multinationals Operating in the Chinese Market. International Journal of Business and Management, 3(12), 169-174. 